\title{
Facile synthesis of iron oxide nanoparticle and synergistic effect of iron nanoparticle in the presence of sunlight for the degradation of DOM from textile wastewater
}

\author{
Fahmida Parvin ${ }^{1,2} \cdot$ Omme Kulsum Nayna ${ }^{1,3} \cdot$ Shafi M. Tareq $^{1} \cdot$ Sharmin Yousuf Rikta ${ }^{1,4} \cdot$ Abdul KI Kamal $^{1}$
}

Received: 15 October 2017 / Accepted: 19 April 2018 / Published online: 4 May 2018

(C) The Author(s) 2018

\begin{abstract}
This study explores the capacity of synthesized $\mathrm{Fe}_{2} \mathrm{O}_{3}$ nanoparticles (NPs) under sunlight for the degradation of dissolved organic matter (DOM) from synthetic (Procion blue dye) solution as well as from textile wastewater (TWW). $\mathrm{Fe}_{2} \mathrm{O}_{3} \mathrm{NPs}_{\text {sere }}$ properly synthesized and confirmed by UV absorbance, FTIR spectra and SEM image analysis. Photocatalytic degradation of DOM from TWW and synthetic solution was performed by catalyst $\mathrm{Fe}_{2} \mathrm{O}_{3} \mathrm{NPs}(5 \mathrm{mg} / \mathrm{L})$ in the presence of solar irradiation (up to $40 \mathrm{~h}$ ). The DOM degradation of the TWW and synthetic solution has been analyzed by fluorescence 3D excitation emission matrix (3D EEM). Synergistic effect was expected and it was found that the rate of decrease of fluorescence intensity increased with time. Within $20 \mathrm{~h}$, for the synthetic solution, reduction of fluorescence intensity (80\%) reaches an equilibrium. In contrast, the rate of decrease in the fluorescence intensity is highest (91\%) in $40 \mathrm{~h}$ of irradiation for TWW. This reduction of fluorescence intensity indicates the degradation of DOM and can be expressed well by second-order model kinetics. Reduction of TOC, $\mathrm{BOD}_{5}$ and COD load again validated the degradation of DOM from TWW by catalyst $\mathrm{Fe}_{2} \mathrm{O}_{3}$ NPs-induced solar irradiation. We applied the treated wastewater on the plant to observe the reusability of the treated TWW, and the morphological data analysis of the plant demonstrates that the catalyst $\mathrm{Fe}_{2} \mathrm{O}_{3}$ NPs-induced solar-irradiated wastewater exhibits less adverse impact on plant morphology.
\end{abstract}

Keywords Iron nanoparticle $\cdot$ Textile wastewater $\cdot 3 D$ EEM

\section{Introduction}

The textile industry is the main creator of effluent wastewater in Bangladesh, due to a greater consumption of water for its different wet and dye processing operations. This effluent wastewater has been recognized to have high color, high BOD and COD load, as well as high dissolved organic

Fahmida Parvin

fahmidaprvn497@gmail.com

1 Department of Environmental Sciences, Jahangirnagar University, Savar, Dhaka 1342, Bangladesh

2 Graduate School of Environmental Science, Hokkaido University, Sapporo 060-0819, Japan

3 Department of Environmental Science and Engineering, Ewha Womans University, Seoul 03760, Republic of Korea

4 Department of Environmental Science, Bangladesh University of Professionals, Mirpur Cantonment, Dhaka 1216, Bangladesh matter (DOM) concentration (Paul et al. 2012). According to the World Bank estimation, textile dyeing and finishing treatment given to a fabric generates around $17-20 \%$ of industrial wastewater (Kant 2012). Selection of the suitable method and material for the sustainable textile wastewater (TWW) treatment is a highly complex task, where we have to consider four factors, quality standard to be met, the treatment efficiency, the cost of treatment and also the reusability of the treated water (Huang et al. 2008; Zhang and Fang 2010; Oller et al. 2011). In an effort to combat the problem of water pollution, rapid and significant progresses in wastewater treatment have been made, including photocatalytic oxidation, adsorption/separation processing and bioremediation (Long et al. 2011; Pang et al. 2011; Parvin et al. 2015, 2017). However, their applications have been restricted by many factors, such as processing efficiency, operational method, energy requirements and economic benefit. Recently, nanomaterials (NMs) have been suggested to be efficient, cost-effective and environmental friendly alternative to existing treatment materials, from the standpoints 
of both resource conservation and environmental remediation (Dimitrov 2006; Dastjerdi and Montazer 2010).

Degradation of DOM and azo dye of water using semiconductor oxide nanomaterials-based photocatalysts is a useful process, where pollutants are mineralized by the photocatalytic mechanism (Akhavan and Azimirad 2009). Photocatalysis refers to the rate of photoreactions (oxidation/ reduction) brought on by the activation of a catalyst, usually a semiconductor oxide, through illumination under ultraviolet (UV) or visible light. The direct band-gap excitation of semiconductors generates electron-hole pairs, which participate in reduction and oxidation processes. Among numerous oxide semiconductor photocatalysts (e.g., $\mathrm{TiO}_{2}, \mathrm{ZrO}_{2}$, $\mathrm{ZnO}, \mathrm{MoO}_{3}, \mathrm{SnO}_{2}, \alpha-\mathrm{Fe}_{2} \mathrm{O}_{3}$ ), anatase crystalline forms of $\mathrm{Fe}_{2} \mathrm{O}_{3}$ and $\mathrm{TiO}_{2}$ nanomaterial are suitable photocatalysts, as those are nontoxic and have vigorous oxidizing capacity (Park and Choi 2004; Nagaveni et al. 2004; Zou et al. 2001). However, one limitation of $\mathrm{TiO}_{2}$ is that it mainly absorbs UV light, which covers only $4-6 \%$ of the solar spectrum. In this regard, iron oxide nanoparticle $\left(\mathrm{Fe}_{2} \mathrm{O}_{3} \mathrm{NP}\right)$ with band gap around $2.3 \mathrm{eV}$ is a suitable candidate to absorb solar light, greater surface area and be used as a photocatalyst.

Akhavan and Azimirad (2009) use mercury lamp as a source of visible light prior to investigating the effect of semiconductor nanocatalyst in dye removal and wastewater treatment. However, using this kind of source is not viable in pilot-scale work or in practical application. Hence, use of direct sunlight is more practicable (Bishnoi et al. 2018) because of its availability. In addition, because of the geographical position of Bangladesh, total solar insolation that reaches different locations of Bangladesh vary from 4 to 5 $\mathrm{kWh} / \mathrm{m}^{2} /$ day, whereas the global solar insolation varies from 3.8 to $6.4 \mathrm{~kW} \mathrm{~h} / \mathrm{m}^{2} /$ day (Nandi et al. 2012). Thus considering the fact, it is wise to use direct sunlight to elucidate the effect of nano-photocatalyst.

Recently, Fe-doped $\mathrm{TiO}_{2}$ photocatalysts and $\mathrm{Fe}_{2} \mathrm{O}_{3}-\mathrm{TiO}_{2}$ coupled semiconductor photocatalysts have been designed for photodegradation of toxic and organic pollutant substances in visible light (Akhavan and Azimirad 2009). However, we always look for those techniques which are inexpensive and easy to prepare. Hence, several laboratories have examined the efficiency of $\mathrm{Fe}_{2} \mathrm{O}_{3} \mathrm{NPs}$ (without doping) during the photocatalytic purification of dye mixed water (Bandra et al. 2001; Cunningham et al. 1988; Fernandez et al. 1998). However, another big problem in wastewater is DOM. The presence of DOM not only affects the current discharge standards, but also presents significant challenges in wastewater reclamation (Gou et al. 2011). DOM contains large amounts of unsaturated and aromatic structures with different functional groups that have fluorescence characteristics, which allows for the utilization of fluorescence spectroscopy to extract information on the degradation of DOM at the time of TWW treatment. In particular, DOM includes organic molecules with chromophoric (light absorbing) and fluorophoric (light emitting) moieties (Wang et al. 2009). Therefore, three-dimensional excitation emission matrix (3DEEM) fluorescence spectroscopy has been widely used to detect detailed changes and transformations of organic matter in wastewater (Wang et al. 2009).

In this study, $\mathrm{Fe}_{2} \mathrm{O}_{3} \mathrm{NPs}$ have been synthesized and, for the first time, the efficacy of $\mathrm{Fe}_{2} \mathrm{O}_{3} \mathrm{NPs}$ as a photocatalyst under solar irradiation in degrading DOM from synthetic dye (Procion blue) solution and TWW has been observed using fluorescence spectroscopy and characterized by 3DEEM. Additionally, the effect of the degraded wastewater on plant growth has also been studied to check the reusability of TWW.

\section{Experimental}

\section{Synthesis of $\mathrm{Fe}_{2} \mathrm{O}_{3} \mathrm{NPs}$}

We synthesized the $\mathrm{Fe}_{2} \mathrm{O}_{3}$ NPs according to the method described in Rahman et al. (2011). In brief, both $\mathrm{FeCl}_{3}$ and urea were slowly dissolved in de-ionized water separately at room temperature to make $0.5 \mathrm{M}$ concentration of $\mathrm{FeCl}_{3}$ and urea solution. Then the solutions were mixed gently and stirred until the two solutions mixed properly. The $\mathrm{pH}$ of the solution was adjusted using ammonia solution dropwise to approximately 9.66. Then the mixture was put into a hydrothermal cell (Teflon line autoclave) to be placed in an oven for $6 \mathrm{~h}$ at $150{ }^{\circ} \mathrm{C}$. Then the solution was washed with acetone and kept for drying at room temperature (Rahman et al. 2011).

\section{Characterization of $\mathrm{Fe}_{2} \mathrm{O}_{3} \mathrm{NPs}$}

The structural and optical properties of the synthesized $\mathrm{Fe}_{2} \mathrm{O}_{3} \mathrm{NPs}$ were tested. The $\lambda$-max of the synthesized iron particles was measured using UV/visible spectrophotometer (Shimadzu, Model no: mini-1240). The IR spectra were measured by FTIR spectrophotometer (Shimadzu, Model no-IR Prestige 21) to study the structural properties of the NPs. The FTIR spectrum was taken in a transmittance mode. The spectra were obtained at a resolution of $4 \mathrm{~cm}^{-1}$ in the range of $400-4000 \mathrm{~cm}^{-1}$ in $\mathrm{KBr}$ media. The surface morphology of the synthesized $\mathrm{Fe}_{2} \mathrm{O}_{3}$ NPs was assessed by a scanning electron microscope (SEM) (JSM-630 JEOL, Japan).

\section{Wastewater sampling and photocatalytic irradiation}

TWW used in this work was sampled from a textile industry named Pakiza Group Ltd., which is situated at Savar, Bangladesh. The sample was a mixture of wastewater, discharged 


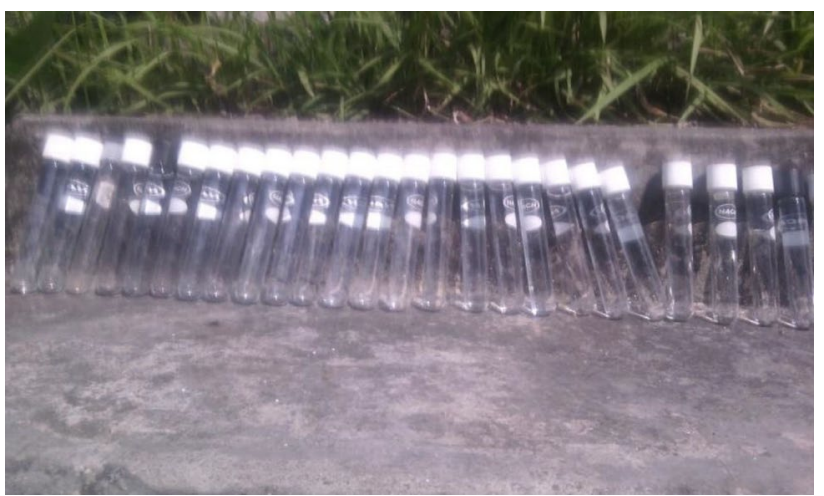

Fig. 1 Solar irradiation of water samples in the presence of $\mathrm{Fe}_{2} \mathrm{O}_{3}$ NPs

from several sections such as washing, dying, waxing and rinsing. The samples $(40 \mathrm{ml})$ were then exposed to solar radiation for up to $40 \mathrm{~h}$ ( 10 days: every day $4 \mathrm{~h}$, from $10 \mathrm{AM}$ to $2 \mathrm{PM}$ ) (both in the presence and absence of catalyst $\mathrm{Fe}_{2} \mathrm{O}_{3}$ NPs) as explained in Bishnoi et al. (2018). Here, a constant catalyst $\left(\mathrm{Fe}_{2} \mathrm{O}_{3} \mathrm{NPs}\right)$ concentration $(5 \mathrm{mg} / \mathrm{L})$ was used. The water samples were kept in vials by adding $\mathrm{Fe}_{2} \mathrm{O}_{3}$ NPs and sealed with cap to avoid evaporation of water (Fig. 1). We conducted this study in February at the rooftop of our laboratory, when the solar insolation for Dhaka was reported to be $4.79 \mathrm{kWh} / \mathrm{m}^{2}$ (Nandi et al. 2012). Similar procedures were also applied for the synthetic dye (Procion blue) solution. We used $40 \mathrm{~mL}$ of synthetic solutions ( $50 \mathrm{mg} / \mathrm{L}$ of dye) and added $5 \mathrm{mg} / \mathrm{L} \mathrm{Fe}{ }_{2} \mathrm{O}_{3} \mathrm{NPs}$. This dye was purchased from Sigma-Aldrich. The properties of the Procion blue (PB) dye are as follows:

- Linear formula: $\mathrm{C}_{23} \mathrm{H}_{14} \mathrm{Cl}_{2} \mathrm{~N}_{6} \mathrm{O}_{8} \mathrm{~S}_{2}$.

- Molecular weight: 637.437.

- Lambda max: $607 \mathrm{~nm}$.

- MDL number: MFCD00001218.

\section{Characterization of the degraded wastewater}

\section{Fluorescent dissolved organic matter degradation study}

The rate of degradation of DOM in dye solution and TWW after photocatalytic solar irradiation was studied by a fluorescence spectrophotometer (F-4600, HITACHI, Tokyo, Japan) by a method described in Tareq et al. 2013 and Yamashita and Tanoue 2003. Briefly, all the samples were filtered through a glass-fiber membrane $(0.45 \mu \mathrm{m})$ to remove suspended materials that may react with DOM. Excitation emission matrices (EEMs) were created using FL Solutions software. Before analysis, water samples were diluted 1000 times to keep the spectra within the upper limit of analysis. To generate an EEM, excitation wavelengths were scanned from 225 to $500 \mathrm{~nm}$ in $5 \mathrm{~nm}$ steps, and the emitted fluorescence detected between 240 and $600 \mathrm{~nm}$ in $2 \mathrm{~nm}$ steps. Excitation and emission slit widths were $5 \mathrm{~nm}$. Scan speed was $1200 \mathrm{~nm} / \mathrm{min}$, permitting collection of a complete EEM in $18 \mathrm{~min}$. Excitation emission matrix (EEM) data were calibrated by normalization to water Raman scattering.

\section{Physicochemical parameter of TWW}

Changes in the environmentally important parameters (BOD, COD, TOC) of the TWW after solar irradiation (both in the presence and absence of catalyst $\mathrm{Fe}_{2} \mathrm{O}_{3} \mathrm{NPs}$ ) were analyzed. The 5-day BOD test of the samples was conducted according to the standard method (ASTM-5210 B). The COD of the samples was determined by the closed reflux colorimetric method (ASTM-5220 D). Total organic carbon (TOC) was measured by the high temperature catalytic oxidation method with a TOC 5000A (Shimadzu, Japan) using potassium hydrogen phthalate (KHP) as a standard (Tareq et al. 2013).

\section{Analysis of the effect of treated wastewater in plant growth}

The treated and raw textile wastewaters were irrigated into Malabar spinach to observe the effect of solar-irradiated textile wastewaters on plant growth using pot experiments. For this purpose, the real TWW was solar irradiated without any dilution both in presence of catalyst iron oxide nanoparticles in a glass reactor which containing at least 71 of wastewater at a time and catalyst (Fig. 2). Every day, 11 of water samples (treated and untreated) was poured on the soil of each pot, where the plant was sown, as described in Parvin et al. (2015). Four pots of Malabar spinach (3 replications) were prepared by adding garden soil with the appropriate moisture content and successively nourished with water, raw and treated textile wastewater. Every week, the plants were monitored prior to measuring the plant morphology to

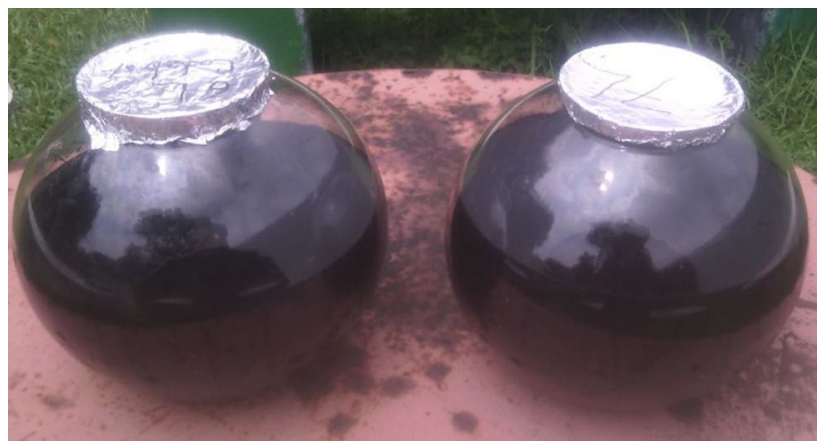

Fig. 2 Solar irradiation of textile wastewater samples in the presence of $\mathrm{Fe}_{2} \mathrm{O}_{3}$ NPs for irrigating on plants 
compare the effect of treated textile effluent with the raw and control one. At 45 DAS (days after sowing) the plants were harvested and the lengths of roots and dry mass were measured. The morphology of the plants was measured according to the method described in Parvin et al. (2013, 2015).

\section{Results and discussion}

\section{Characterizations of $\mathrm{Fe}_{2} \mathrm{O}_{3} \mathrm{NPs}$}

The optical property of the $\mathrm{Fe}_{2} \mathrm{O}_{3}$ NPs is one of the significant properties for determining its optical and photocatalytic activity. The absorption spectrum of as-grown $\mathrm{Fe}_{2} \mathrm{O}_{3} \mathrm{NPs}$ solution was measured by UV-visible spectrophotometer and an onset of absorption maxima was found at $444.0 \mathrm{~nm}$ in the visible range (200-800) $\mathrm{nm}$ wavelength. The lambda maxima of the synthesized NPs are quite similar to those reported by Cornell and Schwertmann (2003) and Rahman et al. (2011) and this wavelength indicates the formation of $\mathrm{Fe}_{2} \mathrm{O}_{3}$ NPs. Band-gap energy is calculated on the basis of the maximum absorption band $(444 \mathrm{~nm})$ of $\mathrm{Fe}_{2} \mathrm{O}_{3} \mathrm{NPs}$. The band-gap energy of NPs was $2.792 \mathrm{eV}$, according to the following equation:

$\operatorname{Ebg}=\frac{1240}{\lambda}(\mathrm{eV})$ where Ebg is the band-gap energy and $\lambda_{\max }$ is the wavelength $(444.0 \mathrm{~nm})$ of the NPs.

FTIR, an excellent tool for recognizing the types of chemical bonds in a molecule, was recorded for $\mathrm{Fe}_{2} \mathrm{O}_{3} \mathrm{NPs}$ (Fig. 3). It displays several bands at 447, 561, 935, 1400, 1630,1751 and $3134 \mathrm{~cm}^{-1}$ and it is known from the literature that $\mathrm{Fe}_{2} \mathrm{O}_{3}$ NPs give absorption bands at those wavelengths (Rahman et al. 2011; Ma and Qi 2007). The band observed at 447.49 and 561.29 represents $\mathrm{Fe}-\mathrm{O}-\mathrm{Fe}$ stretching vibration, and these vibration bands at low frequency regions indicate the formation of $\mathrm{Fe}_{2} \mathrm{O}_{3}$ NPs. The vibration bands observed at 1400 and $1630 \mathrm{~cm}^{-1}$ are assigned to $\mathrm{O}=\mathrm{C}=\mathrm{O}$ stretching and $\mathrm{OH}$ bending vibration. The band observed at $1751.36 \mathrm{~cm}^{-1}$ represents the $\mathrm{C}=\mathrm{O}$ stretching of carbonyl. The strong absorption band at 3032 and $3134.33 \mathrm{~cm}^{-1}$ represents the $\mathrm{C}-\mathrm{H}$ stretching vibration of alkanes and alkenes. Rahman et al. (2011) reported that, the absorption bands at these wavelengths normally arise from the carbon dioxide and water which usually nanomaterials absorbed from the environment due to their mesoporous structure.

The SEM image has been used here to verify the particle size and morphology of $\mathrm{Fe}_{2} \mathrm{O}_{3}$ NPs. Figure 4 shows that the different diameters of NPs grown by the hydrothermal process possessed almost uniform spherical shape. The particles are aggregated with small crystals with a broad size distribution up to $500 \mathrm{~nm}$ (Fig. 4a) and grown at a very high density.

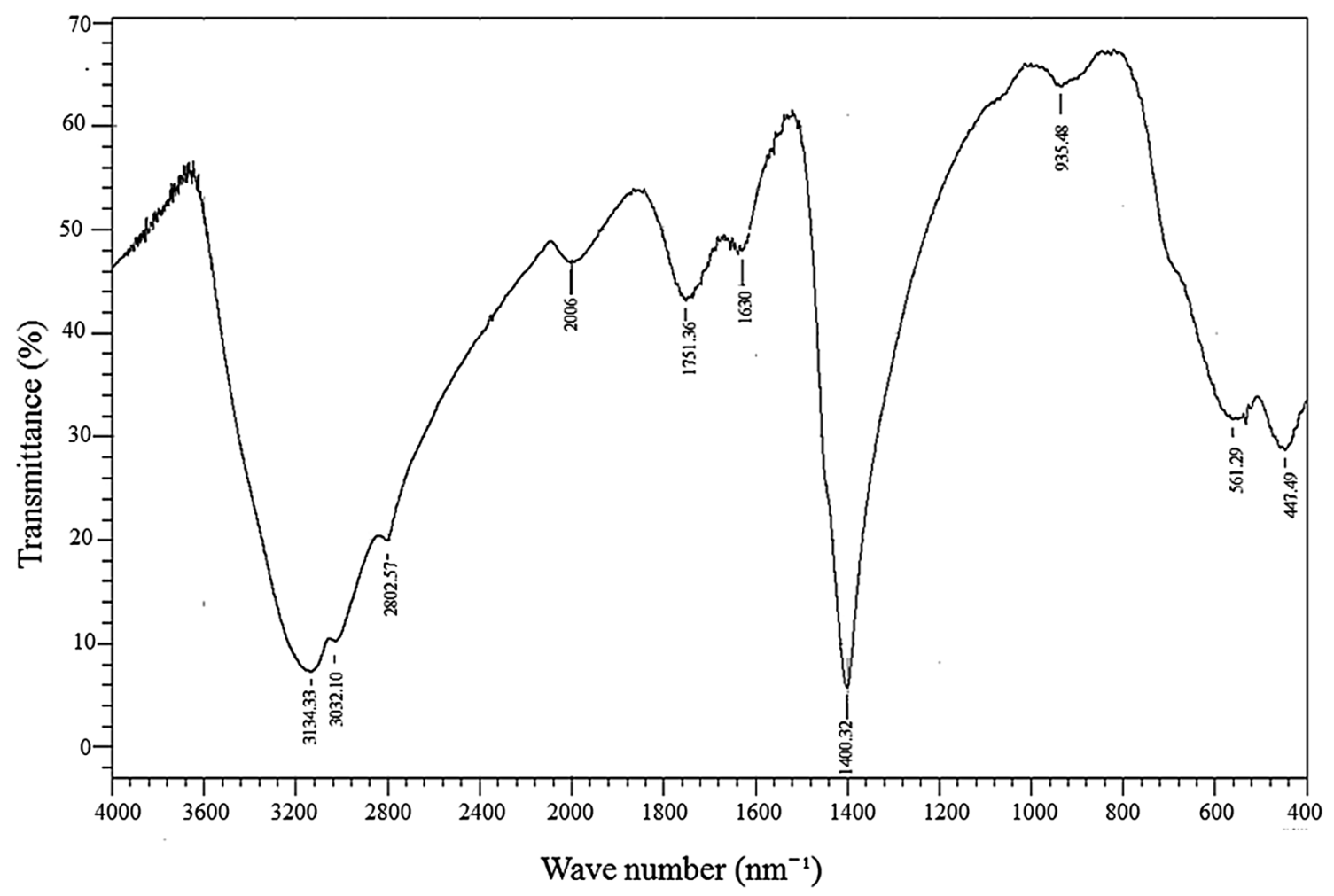

Fig. 3 FTIR spectra of $\mathrm{Fe}_{2} \mathrm{O}_{3}$ NPs 
Fig. 4 High- to low-resolution SEM image of $\mathrm{Fe}_{2} \mathrm{O}_{3} \mathrm{NPs}$

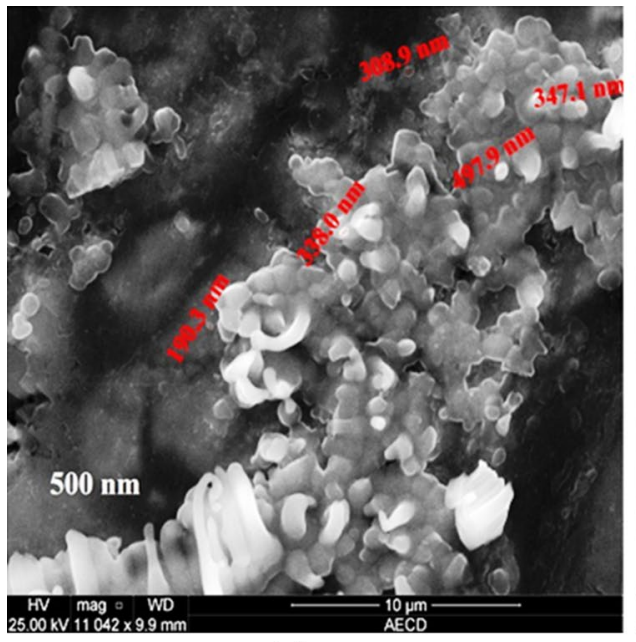

(a)

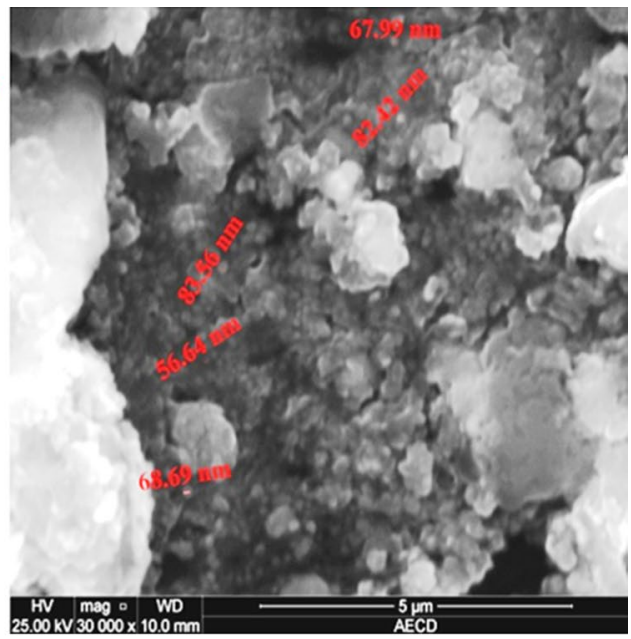

(b)
From this figure, it is clear that the synthesized material is an NP and the morphology of the synthesized iron dioxide NPs is identical. The diameter of the synthesized iron NPs is found in the range of 56-83 nm (Fig. 4b), whereas the average diameter of $\mathrm{Fe}_{2} \mathrm{O}_{3}$ NPs is close to $71 \mathrm{~nm}$ (Rahman et al. 2011). From those analyses, it is clear that $\mathrm{Fe}_{2} \mathrm{O}_{3}$ NPs has been properly synthesized.

\section{Synergistic effect of $\mathrm{Fe}_{2} \mathrm{O}_{3} \mathrm{NPs}$ in the presence of solar radiation for the degradation of DOM from textile wastewater}

\section{Study of fluorescence intensity}

The occurrence of dissolved organic matter is rather common in dye-containing industrial wastewater. Given that $\mathrm{Fe}_{2} \mathrm{O}_{3}$ with a band gap of 2.3-2.7 eV (Akhavan and Azimirad 2009) is an n-type semiconducting material and a suitable candidate for photodegradation of dye compounds under visible light condition and consequently degradation of DOM, we examined the synergistic effect of $\mathrm{Fe}_{2} \mathrm{O}_{3} \mathrm{NPs}$ under solar radiation for the degradation of DOM of dye (PB) solution and TWW (Fig. 5a, b) by means of fluorescence intensity. In the case of synthetic dye (PB) solution (Fig. 5a), the reduction in fluorescence intensity reaches in equilibrium $(80 \%)$ within $20 \mathrm{~h}$ of solar irradiation. When $\mathrm{Fe}_{2} \mathrm{O}_{3}$ NPs are illuminated under visible light, electrons from the valence band jump into the conduction band, causing generation of electrons and positively charged holes and leading to the formation of active oxidation species, which are responsible for enhanced DOM degradation. Generally, the sites near the chromophore (for instance, $\mathrm{C}-\mathrm{N}=\mathrm{N}-$ bond) is the attacked area in the photocatalytic degradation process, and photocatalytic destruction of the $\mathrm{C}-\mathrm{N}=$ and $-\mathrm{N}=\mathrm{N}-$ bonds leads to fading of the dyes (Khataee and

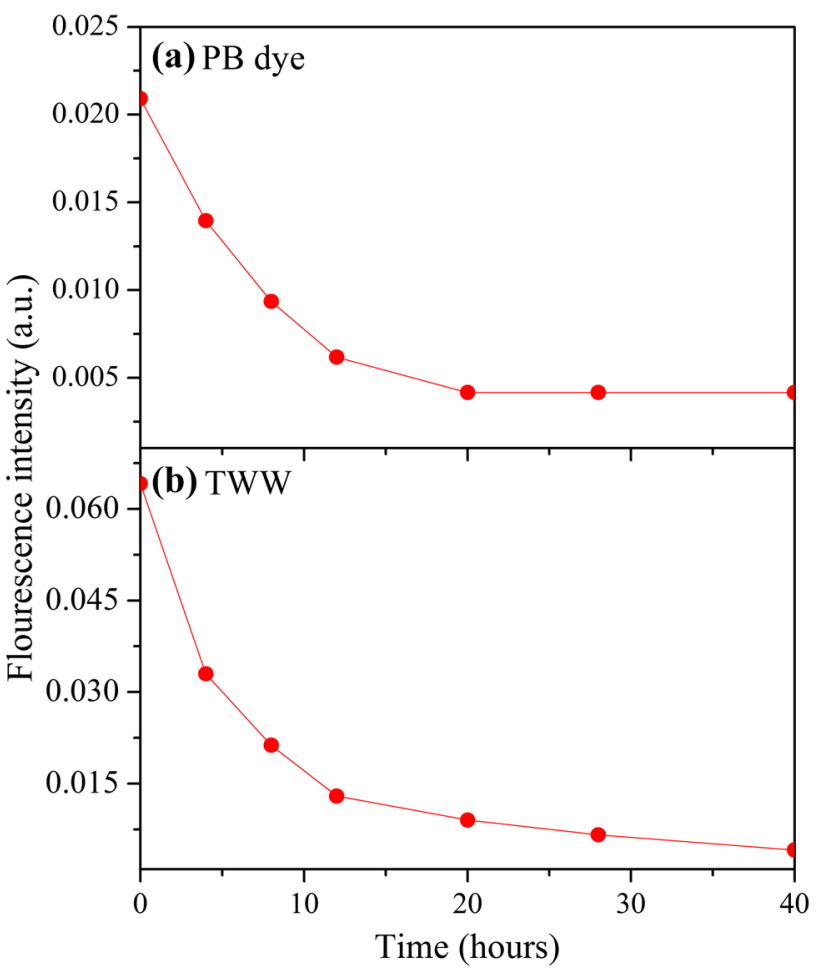

Fig. 5 Time-dependent changes in fluorescence intensity at $350 \mathrm{~nm} / 450 \mathrm{~nm}$ of the PB dye and TWW

Kasiri 2010) and in a consequent degradation of DOM. For TWW, the reduction in fluorescence intensity increases with increase in time (Fig. 5b). Maximum reduction (91\%) was achieved on $40 \mathrm{~h}$ of irradiation.

To investigate the kinetic mechanism of DOM degradation, we looked for the reaction kinetics. We elucidated the reaction kinetics using the fluorescence intensity (a.u.) from 3D EEMs against time, as the fluorescence intensity is

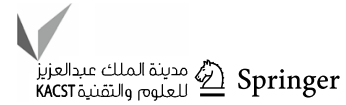


thought to be proportional to the concentration of the analyte (Wang et al. 2009). The first-order reaction rate constant for the reaction was determined by fitting the fluorescence intensities of the samples to the first-order equation:

$\operatorname{Ln}\left(I_{t}\right)=-k_{1} t+\operatorname{Ln}\left(I_{0}\right)$

where $I_{t}$ and $I_{0}$ are the fluorescence intensities at time $t$ and at the initial time. $k_{1}$ is the first-order rate constant. $k_{1}$ and $I_{0 . \text { cal }}$ were calculated from the slope and intercept of the plots of $\operatorname{Ln}\left(I_{t}\right)$ vs. $t$. As for the second-order kinetics, the model can be expressed by the following equation:

$\frac{1}{I_{t}}=k_{2} t+\frac{1}{I_{0}}$,

where $k_{2}$ is the second-order rate constant and $k_{2}$ and $I_{0 \text {.cal }}$ were calculated from the slope and intercept of the plots of $1 / I_{t}$ vs. $t$. The first- and second-order model kinetics of DOM degradation of PB dye and TWW are given in Fig. 6. For both the dye solutions and TWW, the experimental data show relatively lower correlation $\left(R^{2}=0.89-0.96\right)$ in the first-order rate expressions (Fig. 6a, c). In contrast, a high degree of linearity and high correlation $\left(R^{2}=0.99\right)$ with the experimental data were found for second-order rate expression (Fig. 6b, d). These results suggest that the second-order kinetic model is best fitted for describing the DOM degradation from the dye solution, as well as from TWW and the DOM degraded by bimolecular reaction. Here, in Fig. 6a, $\mathrm{b}$, the kinetics for synthetic dye (PB) solution was shown for up to $20 \mathrm{~h}$. As this is a pure dye solution, within $20 \mathrm{~h}$ the rate of degradation reaches an equilibrium stage. We calculate the half-life $\left(t_{1 / 2}\right)$ of second-order reactions using the following equation:

$t_{1 / 2}=\frac{1}{\left(k_{2} \times I_{o}\right)}$,

and the $t_{1 / 2}$ of $\mathrm{Pb}$ dye is $5.02 \mathrm{~h}$. As for TWW, the $t_{1 / 2}$ is $2.99 \mathrm{~h}$.

\section{D EEM analysis}

To examine the extent of DOM degradation in synthetic dye solutions and TWW by $\mathrm{Fe}_{2} \mathrm{O}_{3}$ NPs-induced solar irradiation, 3D excitation emission matrices (EEMs) were created by determining three fluorescent parameters (excitation wavelength, emission wavelength, and the intensity of fluorescence) (Yamashita and Tanoue 2003). The results are arranged in a grid (excitation $\times$ emission $\times$ intensity). The specific excitation and emission wavelengths are characteristics of a particular molecular conformation (i.e., fluorophore) that can indicate the composition of organic compounds. Thus, the measured fluorescent peak intensity (Raman unit, $\mathrm{nm}^{-1}$ ) of DOM is directly related to the concentration of the responsible fluorophore in the sample (Henderson et al. 2009). Here, the rate of DOM degradation increases with increase in irradiation time and we get the best result for $40 \mathrm{~h}$ of irradiation for TWW. However, in the
Fig. 6 First-order $(\mathbf{a}, \mathbf{c})$ and second-order $(\mathbf{b}, \mathbf{d})$ kinetics of the degradation DOM of PB dye and TWW with $\mathrm{Fe}_{2} \mathrm{O}_{3}$ NPs under visible light irradiation

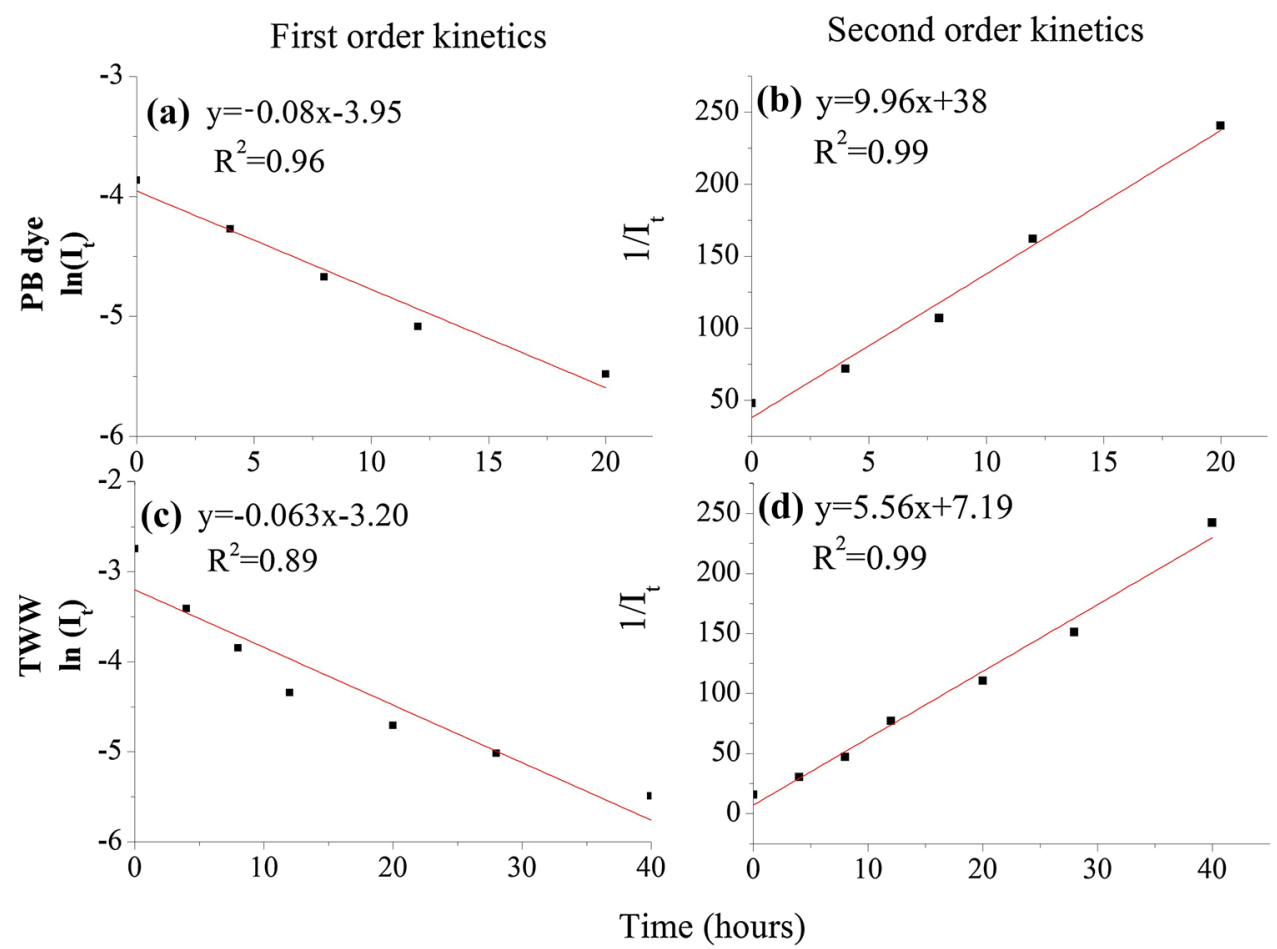


dye solution the rate of degradation reaches in equilibrium within $20 \mathrm{~h}$. Hence, we show the degradation of fluorescent DOM using 3DEEM of synthetic dye solution and TWW only at 20 and $40 \mathrm{~h}$ of irradiation, respectively (Figs. 7, 8).

The fluorescence intensity of the synthetic dye (PB) solution was close to $0.17 \mathrm{RU}$, which decreased to $0.04 \mathrm{RU}$ after $20 \mathrm{~h}$ of photodegradation (Fig. 7a, b). As for TWW, after solar irradiation the relative fluorescence intensity has also decreased (from RU 0.17 to RU 0.10) (Fig. 8). In wastewater samples, the fluorescence peak at around Ex/ $\mathrm{Em}=390-440 \mathrm{~nm} / 442-508 \mathrm{~nm}$ indicates the humic substances (Table 1), which is the specific fluorescence indicator of azo dye in TWW (Li et al. 2015). Additionally, two other peaks at around $E x / E m=300-315 \mathrm{~nm} / 380-382 \mathrm{~nm}$ indicate the protein-like materials and the peak at around $\mathrm{Ex} / \mathrm{Em}=270-295 \mathrm{~nm} / 350-362 \mathrm{~nm}$ indicates fulvic acid. The synergistic effect of $\mathrm{Fe}_{2} \mathrm{O}_{3}$ NPs-induced solar irradiation caused a redshift in excitation emission wavelength of all organic matters and the fluorescence intensity also decreased (Table 1). The resulting redshift could be due to the destruction of various fluorophores (all absorbing at long wavelength) via indirect photochemistry excited at long wavelength. In addition, destruction of fluorophores by direct photochemistry excited at both wavelength or by some means coupled with fluorophores excited at shorter wavelength can also cause redshift in the excitation emission spectra (Coble et al. 2014). If two double bonds are separated by a single bond, the double bonds are termed conjugated. Conjugation of double bonds further induces a redshift in the absorption (a so-called bathochromic shift). From fluorescence spectra analysis, it is clear that irradiation for $40 \mathrm{~h}$ gives best results for TWW. Hence, irradiation for $40 \mathrm{~h}$ was chosen for further analysis with TWW.

\section{Reduction in TOC, COD and BOD of TWW after catalyst-induced solar irradiation}

Fluorescence data of wastewater as well as treated wastewater are thought to well correlate with other parameters including biochemical oxygen demand (BOD), chemical oxygen demand (COD) and total organic carbon (TOC) (Reynolds 2002). In addition, removal of dyes also reduces BOD, COD and TOC of wastewater. Hence, to validate the degradation of DOM of TWW under solar irradiation in the presence of $\mathrm{Fe}_{2} \mathrm{O}_{3} \mathrm{NPs}$, we also measure the environmentally important parameters $\left(\mathrm{BOD}_{5}, \mathrm{COD}\right.$ and TOC) of TWW. Table 2 represents the percent removal of TOC, COD and BOD of TWW after catalystinduced solar irradiation $(40 \mathrm{~h})$. The BOD, COD and TOC of

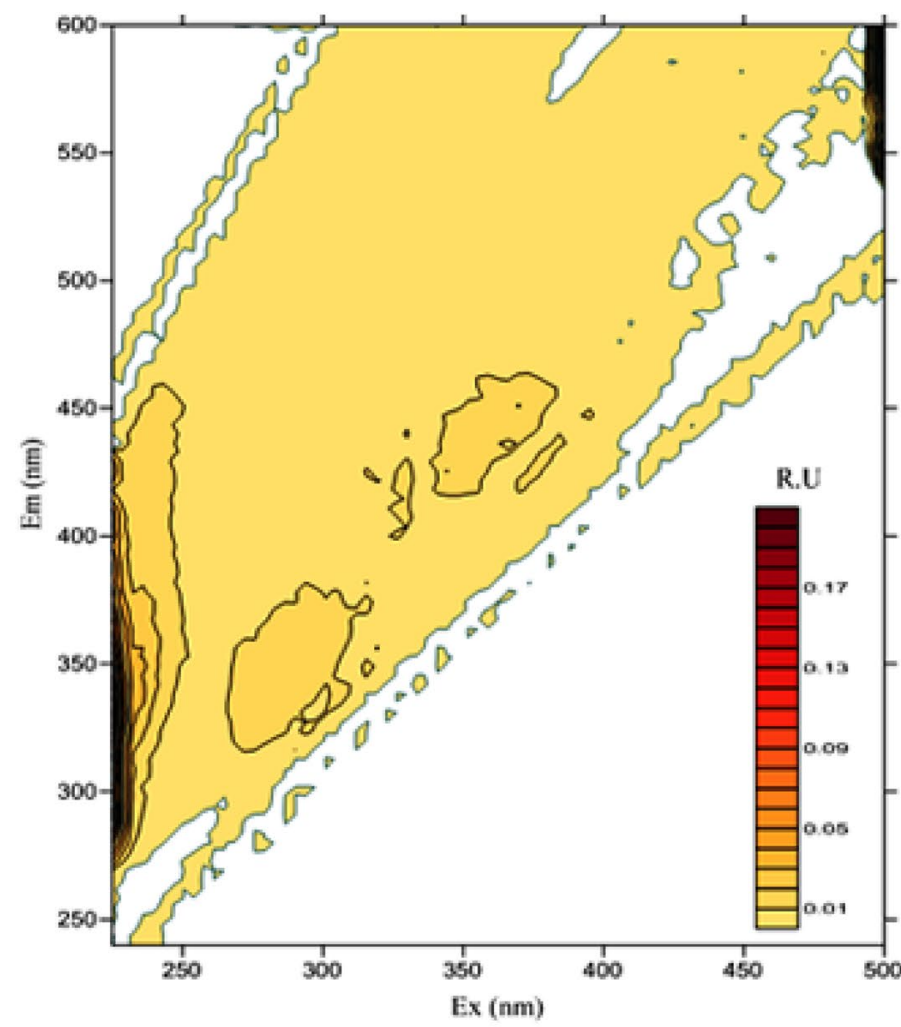

(a)

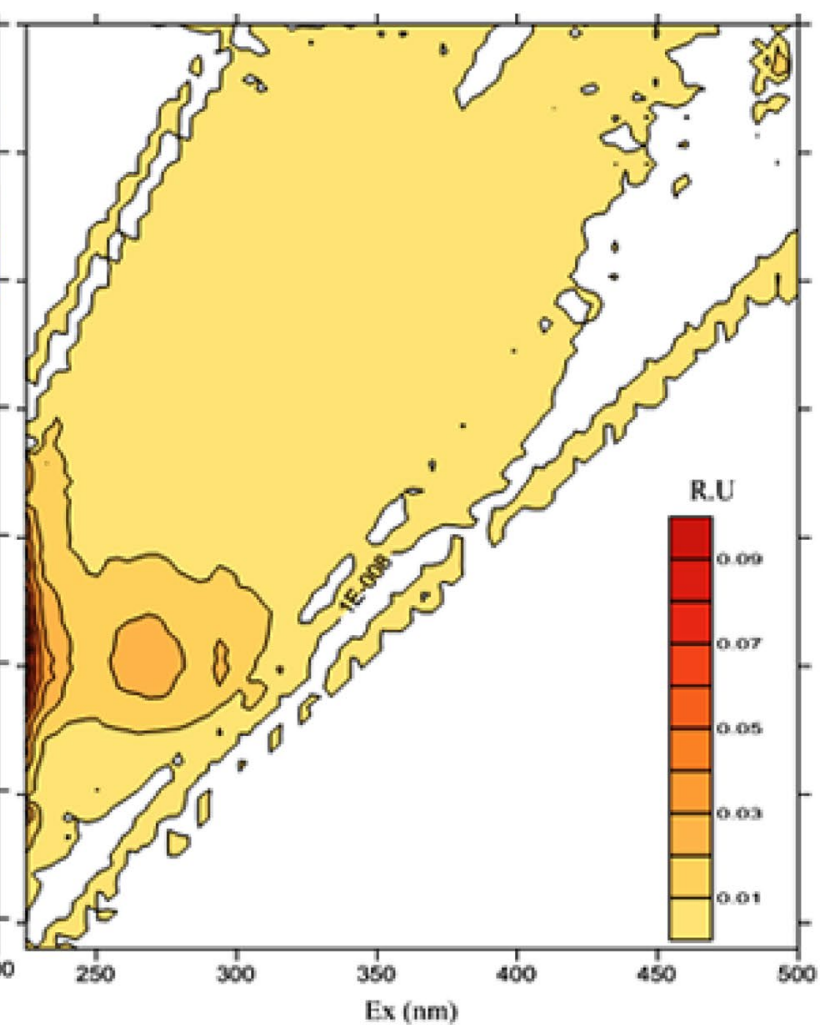

(b)

Fig. 7 A representative illustration of the three-dimensional excitation emission matrix (3DEEM) fluorescence spectra of PB dye solution. a Raw solution, $\mathbf{b}$ at $20 \mathrm{~h}$ of irradiation in the presence of $\mathrm{Fe}_{2} \mathrm{O}_{3} \mathrm{NPs}$ 


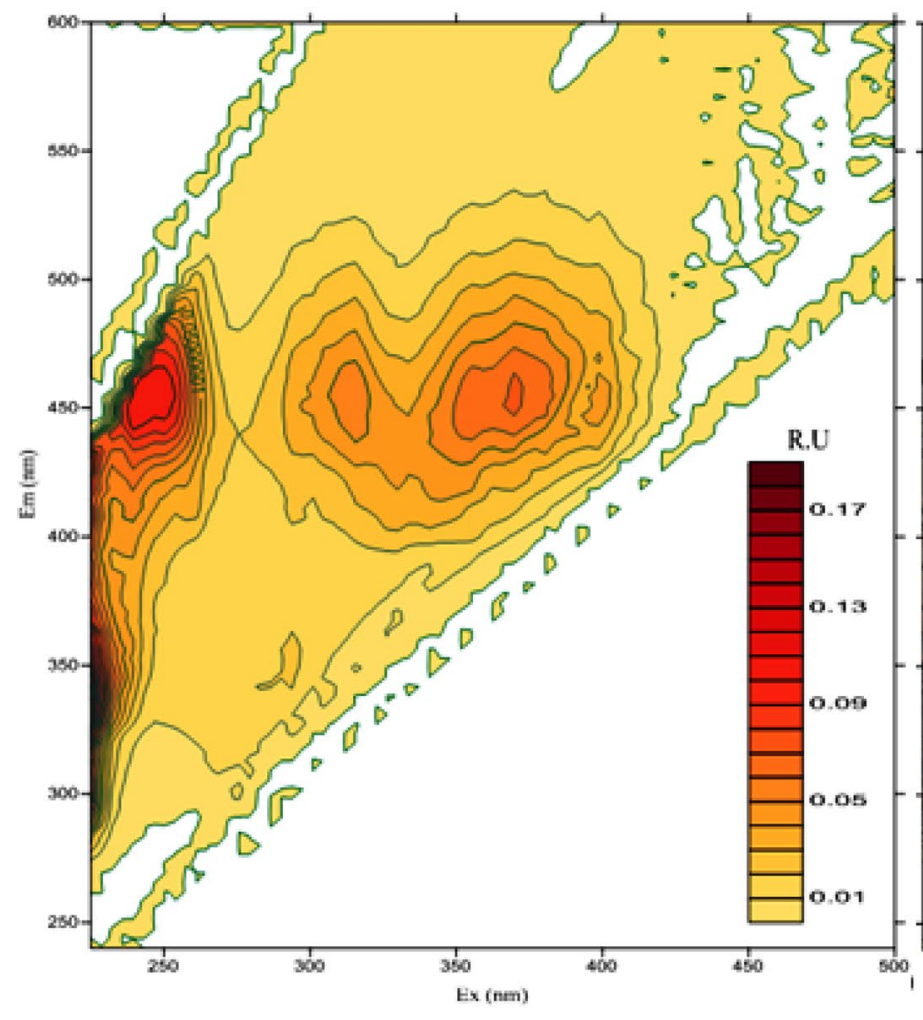

(a)

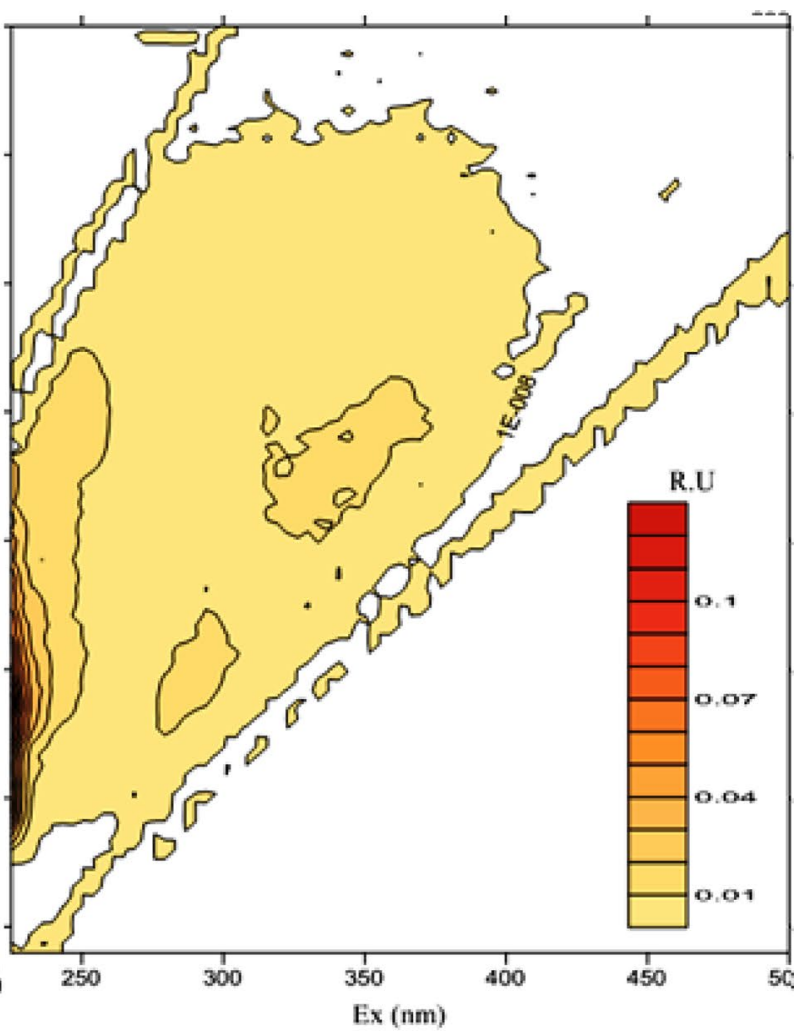

(b)

Fig. 8 A representative illustration of three-dimensional excitation emission matrix (3DEEM) fluorescence spectra of wastewater. a Raw wastewater, $\mathbf{b}$ at $40 \mathrm{~h}$ of irradiation in the presence of $\mathrm{Fe}_{2} \mathrm{O}_{3} \mathrm{NPs}$

Table 1 Fluorescence properties of Procion blue dye and textile wastewater

\begin{tabular}{lccc}
\hline Samples & \multicolumn{3}{l}{ Peak intensities with coordinates (excitation/emission wavelengths) } \\
\cline { 2 - 4 } & Peak 1 & Peak 2 & Peak 3 \\
\hline Procion blue dye solution & $0.06(375 \mathrm{~nm} / 460 \mathrm{~nm})$ & $0.07(365 \mathrm{~nm} / 452 \mathrm{~nm})$ & $0.02(295 \mathrm{~nm} / 354 \mathrm{~nm})$ \\
$\mathrm{Raw}$ & $0.007(380 \mathrm{~nm} / 432 \mathrm{~nm})$ & $0.01(340 \mathrm{~nm} / 434 \mathrm{~nm})$ & $0.01(280 \mathrm{~nm} / 308 \mathrm{~nm})$ \\
$\mathrm{Fe}_{2} \mathrm{O}_{3}$ induced & & \\
$\quad$ solar irradiated & & & \\
$\quad$ for 20 h days & & $0.01(300 \mathrm{~nm} / 380 \mathrm{~nm})$ & $0.01(270 \mathrm{~nm} / 350 \mathrm{~nm})$ \\
Textile wastewater & $0.01(390 \mathrm{~nm} / 442 \mathrm{~nm})$ & $0.009(315 \mathrm{~nm} / 382 \mathrm{~nm})$ & $0.01(295 \mathrm{~nm} / 362 \mathrm{~nm})$ \\
$\mathrm{Raw}_{\mathrm{Fe}} \mathrm{O}_{3}$ induced & $0.008(440 \mathrm{~nm} / 508 \mathrm{~nm})$ & & \\
$\quad$ solar irradiated & & & \\
for 40 h & & & \\
\hline
\end{tabular}

Table 2 Reduction in TOC, COD and BOD of real textile wastewater after the treatment process $(40 \mathrm{~h})$

\begin{tabular}{llll}
\hline & BOD (\%) & COD (\%) & TOC (\%) \\
\hline $\begin{array}{l}\text { After catalyst-induced solar irradia- } \\
\text { tion days }\end{array}$ & 37.89 & 44.68 & 42.2 \\
\hline
\end{tabular}

TWW are 208, 409 and $89 \mathrm{mg} / \mathrm{L}$, respectively. Data in Table 2 indicates that all those properties were improved after $40 \mathrm{~h}$ of solar irradiation with catalyst $\mathrm{Fe}_{2} \mathrm{O}_{3} \mathrm{NPs}$. After $40 \mathrm{~h}$ of photocatalytic irradiation, TOC, COD and BOD were reduced by 42.2, 44.68 and $37.89 \%$, respectively. By the influence of solar irradiation in the presence of $\mathrm{Fe}_{2} \mathrm{O}_{3} \mathrm{NPs}$, complex organic compounds are converted to simple compounds such as carbon dioxide, water, nitrate, amide and carboxylic acids (Hussein and Abbas 2010; Xu et al. 2012) and consequently the BOD, COD load and TOC of TWW are decreased. This result again 
proves the degradation of DOM from TWW using $\mathrm{Fe}_{2} \mathrm{O}_{3}$ NPs under solar irradiation. However, the improvement rate is less in comparison to some other treatment, i.e., at $10 \mathrm{kGy}$ direct gamma irradiation, the BOD and COD of TWW reduced by 59 and 61\%, respectively (Parvin et al. 2015). These rates of reduction (Table 2) suggest that degradation compounds, especially low molecular weight aldehydes and organic acids, still remain in solution. So, it is recommended that, to achieve complete mineralization, a little higher concentration of $\mathrm{Fe}_{2} \mathrm{O}_{3}$ NPs in wastewater is necessary.

\section{Effect of degraded wastewater on plant growth}

Textile wastewaters are thought to hinder plant growth (Parvin et al. 2015), as the water quality is worse compared to the standard for use for irrigation purpose. Hence, the treated wastewater was irrigated to plants to compare the effect of treated wastewater on plant growth with raw wastewater. Figure 9 represents the morphological parameter of Malabar spinach nourished by water (control), TWW and catalyst-induced solar-irradiated TWW (TWW1), respectively. The morphological data (e.g., plant height, number of leaves, root length and dry mass) given in Fig. 9 were measured after 45 days as shown. As expected, plants irrigated by TWW showed very low morphological properties in comparison with plants treated with normal water, because wastewaters having low DO, higher concentration of DOM and BOD load hinder plant growth. However, when we nourish the plants with catalyst-induced solar-irradiated wastewater, the value of plant growth becomes higher, though these values of plant morphology are still less in comparison to the values of the control. However, in our previous work (Parvin et al. 2015), we decolorized TWW, using ionizing gamma irradiation, which showed a fertilizing effect on plant growth. The possible explanation is solar radiation is not so intense like the most penetrating ionizing gamma irradiation to break the azo dye completely into nitrogen and ammonia, which is the reason for suppressing the plant growth (though little), instead of acting as a fertilizer. However, using solar radiation is cost-effective and renewable compared to gamma radiation, as gamma radiation plants require high maintenance cost and the source $\mathrm{Co}^{60}$ is not renewable. Hence, the use of a relatively high concentration of $\mathrm{Fe}_{2} \mathrm{O}_{3}$ NPs (more than $5 \mathrm{mg} / \mathrm{l}$ ) to accelerate the degradation ability of solar radiation is recommended in degrading the dye and DOM completely.

\section{Conclusions}

We synthesized properly $\mathrm{Fe}_{2} \mathrm{O}_{3}$ NPs and it has also been proved by UV-Vis, FTIR spectra and SEM images analysis. Degradation of DOM of the dye solution and TWW

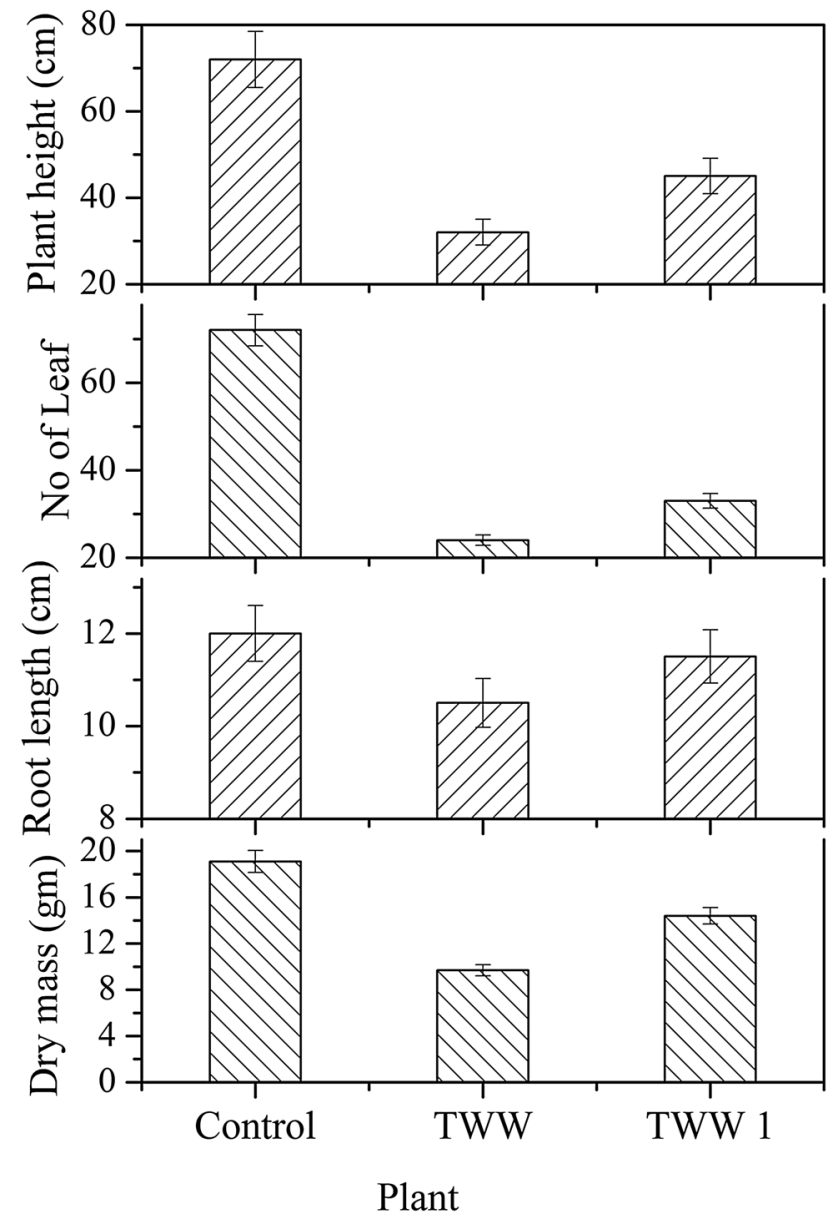

Fig. 9 Morphological properties of Malabar spinach after irrigation with water (control), wastewater (TWW) and catalyst-induced irradiated wastewater (TWW1)

linearly increased with time and the best results were found at $40 \mathrm{~h}$ of solar irradiation for TWW. As for $\mathrm{Pb}$ dye solution of $50 \mathrm{mg} / \mathrm{L}$ concentration, the rate of degradation (80\%) reached in equilibrium within $20 \mathrm{~h}$ using $5 \mathrm{mg} / \mathrm{l} \mathrm{Fe}{ }_{2} \mathrm{O}_{3}$ NPs. The degradation of fluorescent DOM of textile wastewater and dye solution by means of fluorescence intensity can be described well by the second-order kinetic model. Analysis of 3DEEM revealed that, after photocatalytic irradiation, the intensity of humic acid is reduced, which is the main florescence indicator of azo dye in TWW. The degradation of DOM is again supported by the reduction of BOD, COD and TOC of TWW, indicating the applicability of this method (use of nanocatalyst under sunlight) in open lagoon/pond of the textile wastewater treatment plant. The catalyst-induced solar-irradiated wastewater is found to have less effect on plant growth compared to raw wastewater. However, a little higher concentration of $\mathrm{Fe}_{2} \mathrm{O}_{3}$ NPs is recommended for the complete degradation of DOM. Hence, in our next work, we will focus on catalyst $\mathrm{Fe}_{2} \mathrm{O}_{3}$ NPs concentration-dependent dye

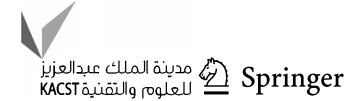


and the DOM degradation of synthetic dye solution and TWW.

Open Access This article is distributed under the terms of the Creative Commons Attribution 4.0 International License (http://creativeco mmons.org/licenses/by/4.0/), which permits unrestricted use, distribution, and reproduction in any medium, provided you give appropriate credit to the original author(s) and the source, provide a link to the Creative Commons license, and indicate if changes were made.

\section{References}

Akhavan O, Azimirad R (2009) Photocatalytic property of $\mathrm{Fe}_{2} \mathrm{O}_{3}$ nanograin chains coated by $\mathrm{TiO}_{2}$ nanolayer in visible light irradiation. Appl Catal A Gen 369(1-2):77-82. https://doi. org/10.1016/j.apcata.2009.09.001

Bandara J, Mielczarski JA, Kiwi J (2001) Sensitized degradation of chlorophenols on iron oxides induced by visible light: comparison with titanium oxide. Appl Catal B Environ 34:321-333. https://doi.org/10.1016/S0926-3373(01)00225-9

Bishnoi S, Kumar A, Selvaraj R (2018) Facile synthesis of magnetic iron oxide nanoparticles using inedible Cynometra ramiflora fruit extract waste and their photocatalytic degradation of methylene blue dye. Mater Res Bull 97:121-127. https://doi. org/10.1016/j.materresbull.2017.08.040

Coble PG, Lead J, Baker A, Reynolds DM, Spencer RGM (2014) Aquatic organic matter fluorescence. Cambridge University Press, New York

Cornell RM, Schwertmann U (2003) The iron oxides-structure, properties, reactions, occurrences and uses. Wiley-VCH GmbH \& Co. KGaA, Darmstadt

Cunningham K, Goldberg MC, Weiner ER (1988) Mechanisms for aqueous photolysis of adsorbed benzoate, oxalate, and succinate on iron oxyhydroxide (goethite) surfaces. Environ Sci Technol 22:1090-1097

Dastjerdi R, Montazer M (2010) A review on the application of inorganic nano-structured materials in the modification of textiles: focus on anti-microbial properties. Colloid Surf B 79(1):5-18. https://doi.org/10.1016/j.colsurfb.2010.03.029

Dimitrov D (2006) Interactions of antibody-conjugated nanoparticles with biological surfaces. Colloids Surf A Physicochem Eng Asp 282-283:8-10

Fernandez J, Bandara J, Lopez A, Albers P, Kiwi J (1998) Efficient photo-assisted Fenton catalysis mediated by Fe ions on Nafion membranes active in the abatement of non-biodegradable azodye. Chem Commun 14:1493-1494

Guo J, Peng Y, Guo J, Ma J, Wang W, Wang B (2011) Dissolved organic matter in biologically treated sewage effluent (BTSE): characteristics and comparison. Desalination 278(1-3):365372. https://doi.org/10.1016/j.desal.2011.05.057

Henderson RK, Baker A, Murphy KR, Hamblya A, Stuetz RM, Khan SJ (2009) Fluorescence as a potential monitoring tool for recycled water systems: a review. Water Res 43(4):863-881. https ://doi.org/10.1016/j.watres.2008.11.027

Huang DL, Zeng GM, Feng CL, Hu S, Jiang XY, Tang L (2008) Degradation of lead contaminated lignocellulosic waste by Phanerochaete chrysosporium and the reduction of lead toxicity. Environ Sci Technol 42(13):4946-4951

Hussein FH, Abbas TA (2010) Photocatlytic treatment of textile industrial wastewater. Int J Chem Sci 8(3):1353-1364

Kant R (2012) Textile dyeing industry an environmental hazard. Nat Sci 4(2012):22-26. https://doi.org/10.4236/ns.2012.41004
Khataee AR, Kasiri MB (2010) Photocatalytic degradation of organic dyes in the presence of nanostructured titanium dioxide: Influence of the chemical structure of dyes. J Mol Catal A Chem 328(1-2):8-26. https://doi.org/10.1016/j.molcata.2010.05.023

Li WT, Xu ZX, Wu Q, Li Y, Shuang CD, Li AM (2015) Characterization of fluorescent dissolved organic matter and identification of specific fluorophores in textile effluents. Environ Sci Pollut Res 22:4183-4189

Long F, Gong JL, Zeng GM, Chen L, Wang XY, Deng JH (2011) Removal of phosphate from aqueous solution by magnetic $\mathrm{Fe}-$ Zr binary oxide. Chem Eng J 171:448-455

Ma H, Qi X (2007) Maitanihttp://www.sciencedirect.com/science/ article/pii/S0378517306008131—aff2 Y, Nagai http://www. sciencedirect.com/science/article/pii/S0378517306008131aff2T. Preparation and characterization of super paramagnetic iron oxide nanoparticles stabilized by alginate. Int J Pharm 333(1-2):177-186

Nagaveni K, Hegde MS, Ravishankar N, Subbanna GN, Madrad G (2004) Synthesis and structure of nanocrystalline $\mathrm{TiO}_{2}$ with lower band gap showing high photocatalytic activity. Langmuir 20:2900

Nandi SK, Hoque MN, Ghosh HR, Roy SK (2012) Potential of wind and solar electricity generation in Bangladesh. ISRN Renew Energy. https://doi.org/10.5402/2012/401761

Oller I, Malato S, Sánchez-Pérez JA (2011) Combination of advanced oxidation processes and biological treatments for wastewater decontamination: a review. Sci Total Environ 409(20):4141-4166

Pang Y, Zeng GM, Tang L, Zhang Y, Liu YY, Lei XX et al (2011) PEI-graftedmagnetic porous powder for highly effective adsorption of heavy metal ions. Desalination 281:278-284

Park H, Choi W (2004) Effects of $\mathrm{TiO}_{2}$ surface fluorination on photocatalytic reactions and photoelectrochemical behaviors. J Phys Chem B 108(13):4086

Parvin F, Yeasmin F, Islam JMM, Molla E, Khan MA (2013) Effect of gamma irradiated sodium alginate on Malabar Spinach (Basella alba) and Spinach (Spinacia oleracea) as plant growth promoter. Am Acad Scholar Res J 5(5):63-71

Parvin F, Ferdaus Z, Tareq SM, Choudhury TR, Islam JMM, Khan MA (2015) Effect of gamma-irradiated textile effluent on plant growth. Int J Recycl Org Waste Agricult 4:23-30

Parvin F, Sultana N, Habib SMA, Bhoumik NC (2017) Gamma irradiation and steam pretreatment of jute stick powder for the enhancement of dye adsorption efficiency. Appl Water Sci. https ://doi.org/10.1007/s13201-017-0617-2

Paul S, Chavan SK, Khambe SD (2012) Studies on characterization of textile industrial waste water in solapur city. Int J Chem Sci 10:635-642

Rahman MM, Khan SB, Jamal A, Faisal M, Aisiri AM (2011) Iron oxide nanoparticles, nanomaterials, Prof. Mohammed Rahman (ed.) https://doi.org/10.5772/27698. https://www.intechopen .com/books/nanomaterials/iron-oxide-nanoparticles

Reynolds D (2002) The differentiation of biodegradable and nonbiodegradable dissolved organic matter in wastewaters using fluorescence spectroscopy. J Chem Technol Biotechnol 77:965972. https://doi.org/10.1002/jctb.664

Tareq SM, Marou M, Otha K (2013) Characteristics and role of groundwater dissolved organic matter on arsenic mobilization and poisoning in Bangladesh. Phys Chem Earth Parts A/B/C 58-60:77-84

Wang Z, Wu Z, Tang S (2009) Characterization of dissolved organic matter in a submerged membrane bioreactor by using threedimensional excitation and emission matrix fluorescence spectroscopy. Water Res 43(6): 1533-1540

$\mathrm{Xu} \mathrm{P}$ et al (2012) Use of iron oxide nanomaterials in wastewater treatment: a review. Sci Total Environ 424:1-10 
Yamashita Y, Tanoue E (2003) Chemical characterization of proteinlike fluorophores in DOM in relation to aromatic amino acids. Mar Chem 82:255-271

Zhang LD, Fang M (2010) Nanomaterials in pollution trace detection and environmental improvement. Nano Today 5(2):128-142
Zou Z, Ye J, Sayama K, Arakawa H (2001) Direct splitting of water under visible light irradiation with an oxide semiconductor photocatalyst. Nature 414:625

Publisher's Note Springer Nature remains neutral with regard to jurisdictional claims in published maps and institutional affiliations. 